\title{
Effects of Silybin Supplementation on Nutrient Digestibility, Hematological Parameters, Liver Performance, and Liver-specific mi-RNA Concentration in Dogs
}

\author{
Maciej Gogulski \\ University of Life Sciences in Poznań \\ Adam Cieslak \\ University of Life Sciences in Poznań \\ Julia Grabska \\ University of Life Sciences in Poznań \\ Marie Ardois \\ University of Life Sciences in Poznań \\ Małgorzata Pomorska-Mól \\ University of Life Sciences in Poznań \\ Paweł Kołodziejski \\ University of Life Sciences in Poznań \\ Kacper Libera \\ University of Life Sciences in Poznań \\ Viola Strompfová \\ Centre of Biosciences SAS \\ Małgorzata Szumacher-Strabel ( $\square$ malgorzata.szumacher@up.poznan.pl ) \\ University of Life Sciences in Poznań
}

\section{Research Article}

Keywords: sylimarin, supplement, hepatoprotector, nutrition, neutraceuticals, canine

Posted Date: January 23rd, 2021

DOI: https://doi.org/10.21203/rs.3.rs-149461/v1

License: () (1) This work is licensed under a Creative Commons Attribution 4.0 International License.

Read Full License 


\section{Abstract}

\section{Background}

Hepatopathies are an important group of disorders in dogs, where proper nutritional care is crucial. Supplementation with a hepatoprotectant like silybin can improve liver performance, subsequently it should not interfere with nutrient digestibility. The purpose of the study was to investigate the effect of either pure silybin or commercial hepatoprotectant on nutrients digestibility, liver performance and health status in healthy dogs (EXP1). Moreover, the second experiment (EXP2) investigated the effect of commercial hepatoprotectant on liver laboratory test and liver-associated miRNA concentrations in dogs with idiopathic liver disorder.

\section{Results}

Nutrient digestibility was not affected by treatment in EXP1. Supplementation did not affect serum fatty acid profile, with the exception of C20:5 n3. The levels of liver markers such as ALT, AST and GGT significantly decreased. In EXP2, supplementation with commercial hepatoprotectant containing silybin improved liver laboratory test. A decrease was observed in liver serum markers and miR122 concentration.

\section{Conclusions}

EXP1 confirmed that silybin (whether pure or as a commercial hepatoprotectant) does not interfere with digestion and subsequently exerts no detrimental effect on dogs' health and metabolism. In EXP2, dietary supplementation with commercial hepatoprotectant containing silybin resulted in decreased activity of serum liver markers, accompanied by a decrease in the concentration of liver-specific miRNA molecules. Liver performance was consequently improved. Silybin supplementation can thus serve as an effective therapeutical tool in dogs with hepatopathies.

\section{Background}

Pet owners are now more aware of, and responsible for, their animal's welfare. Fortunately, this trend coexists with a rapid increase in the scope of veterinary services, including to dietary counseling [1]. Both pet owners and practitioners should know that an adequate diet is crucial for their animal's good health [2]. The diet is more significant in the case of serious diseases, when proper nutritional care may be a powerful tool for supporting the body's fight against the illness. The veterinary literature describes special dietary recommendations for dogs suffering from heart [3-5], renal [6, 7] or gastrointestinal disorders [6, 8]. Dedicated feeds are often more digestible, having a lowered or elevated concentration of particular ingredients or special additives, which are often secondary plant metabolites [9-11]. These are often referred to as nutraceuticals, a term first defined by Stephen DeFelice in 1989 as an aliment or additive to food which may aid, prevent, or treat a condition by granting medical or health benefits [12]. A particular emphasis should be put on the nutrition of hepatopathic dogs', since liver disorders have high prevalence 
in dogs. According to Watson [13], 12\% of dogs in United Kingdom were postmortem diagnosed with chronic hepatitis. The etiology may vary from infectious agents such as canine adenovirus 1 (CAV-1) or leptospirosis, to non-infectious factors like neoplasia, poisoning, or inherited malformations [14].

Regardless of the underlying problem, appropriate feeding should be considered as an effective means of handling liver diseases. One relevant question is whether nutraceutical supplementation also affects nutrient digestibility. This is worth considering, as patients with hepatic disorders are reported to show signs of gastrointestinal dysfunctions [15-17].

Silybin is a secondary plant metabolite that exhibits health-beneficial properties. Silibinin, composed of silybin A and B isomers, is one of the most active flavonolignans present in the extract of milk thistle (Silybum marianum) [10]. Along with other flavonolignans (isosilibinin, silidianin, and silicristin), it forms a complex known as silymarin. As far as we know, the literature does not discuss silybin as an antinutrient, and there has been no study of its effects on nutrient digestibility. Furthermore, no study has compared pure silybin with commercial hepatoprotectant containing silybin supplementation. For this reason, in the first experiment (EXP1) we hypothesise that supplementation of either pure silybin (SIL) or commercial hepatoprotectant containing silybin (HEP) as a bioactive compound in healthy dogs does not affect nutrient digestibility, a control group (CON) of non-supplemented dogs also took part in the study. We subsequently assumed that supplementation improves liver performance, while not exerting a detrimental effect on general health or blood parameters. In the second experiment (EXP2), we hypothesised that supplementation with commercial hepatoprotectant containing silybin improves liver function in dogs with hepatopathies. The main objectives of this study were thus:

1. to investigate the effects of diet supplemented with either pure silybin or commercial hepatoprotectant containing silybin on nutrient digestibility, general health, immunological parameters (serum cytokines, immunoglobulins, and acute phase protein concentrations), as well as on liver performance in clinically healthy dogs, and

2. to examine the effects of a diet supplemented with commercial hepatoprotectant containing silybin on liver performance in dogs with hepatopathies.

\section{Results}

\section{Clinical Observations and Mortality: EXP1}

During EXP1, all dogs were in good health. No clinical symptoms or mortality was observed.

\section{Chemical composition and fatty acid profile of the diet: EXP1}

The chemical composition of the diet fed to the dogs in EXP1 is given in Table 1, along with its fatty acid profile. 
Table 1

Chemical composition and fatty acid profile of the diet fed to the dogs (EXP1)

\begin{tabular}{|ll}
\hline Item & Value \\
\hline Gross energy $(\mathrm{MJ} / \mathrm{kg})$ & 21.1 \\
\hline Dry matter $(\mathrm{g} / \mathrm{kg})$ & 936 \\
\hline Organic matter $(\mathrm{g} / \mathrm{kg})$ & 867 \\
\hline Crude protein $(\mathrm{g} / \mathrm{kg})$ & 293 \\
\hline Crude fiber $(\mathrm{g} / \mathrm{kg})$ & 62.6 \\
\hline Ether extract $(\mathrm{g} / \mathrm{kg})$ & 138 \\
\hline Crude ash $(\mathrm{g} / \mathrm{kg})$ & 69.0 \\
\hline FA $(\mathrm{g} / 100 \mathrm{~g} \mathrm{FA})$ & \\
\hline C14:0 & 1.73 \\
\hline C16:0 & 17.99 \\
\hline C16:1 & 2.97 \\
\hline C18:0 & 10.55 \\
\hline C18:1 cis 9 & 31.41 \\
\hline C18:2 cis 9 cis 12 & 19.83 \\
\hline C18:3 cis 9 cis 12 cis 15 & 5.63 \\
\hline C20:3n6 & 1.10 \\
\hline C20:5n3 & 0.60 \\
\hline C22:5n3 & 0.60 \\
\hline C22:6n3 & 0.62 \\
\hline Other & 6.97 \\
\hline
\end{tabular}

Abbreviations: UFA, unsaturated fatty acids; MUFA, monounsaturated fatty acids; PUFA, polyunsaturated fatty acids; MCFA, medium chain fatty acids; LCFA, long chain fatty acids; other FAs include C12:0, C14:1, C15:0, C16:1, C18:1 cis-11, C18:1 cis-15, C24:0, and C24:1

\section{Body weight and body condition score: EXP1}

The treatment affected neither body weight (BW) nor the BCS of the studied dogs ( $p$-value $=0.89$ ). At the end of EXP1, the BW of the CON dogs was about $15.5 \mathrm{~kg}$ and was approximately $15.2 \mathrm{~kg}$ and $14.7 \mathrm{~kg}$ for the HEP and SIL dogs, respectively. The BCS was 5 throughout the whole experiment and did not differ between treatments (Table 2). 
Table 2

BW and BCS of dogs fed diets supplemented with silybin and commercial hepatoprotectant (EXP1)

\begin{tabular}{|llllll|}
\hline Item & $\begin{array}{l}\text { CON } \\
(\mathbf{n = 1 8}) \\
\text { mean }\end{array}$ & $\begin{array}{l}\text { HEP } \\
(\mathbf{n = 1 8 )}\end{array}$ & $\begin{array}{l}\text { SIL } \\
(\mathbf{n = 1 8 )}\end{array}$ & SEM & $P$ \\
\hline BW & 15.5 & 15.2 & 14.7 & & \\
\hline BCS & 5 & 5 & 5 & 0.13 & NSD \\
\hline $\begin{array}{l}\text { Abbreviations: BW, body weight; BCS, body condition score; CON, control group; HEP, group fed diet } \\
\text { supplemented with commercial hepatoprotectant containing silybin; NSD, not statistically different; } \\
\text { SIL, group fed diet supplemented with pure silybin. }\end{array}$ \\
\hline
\end{tabular}

\section{Apparent Digestibility: EXP1}

Nutrient and dry matter (DM) digestibility were not affected by the treatment, but higher ether extract digestibility in the CON group differed from that in the HEP and SIL group (Table 3).

Table 3

Apparent nutrient digestibility of dogs fed diet supplemented with silybin and commercial hepatoprotectant (EXP1)

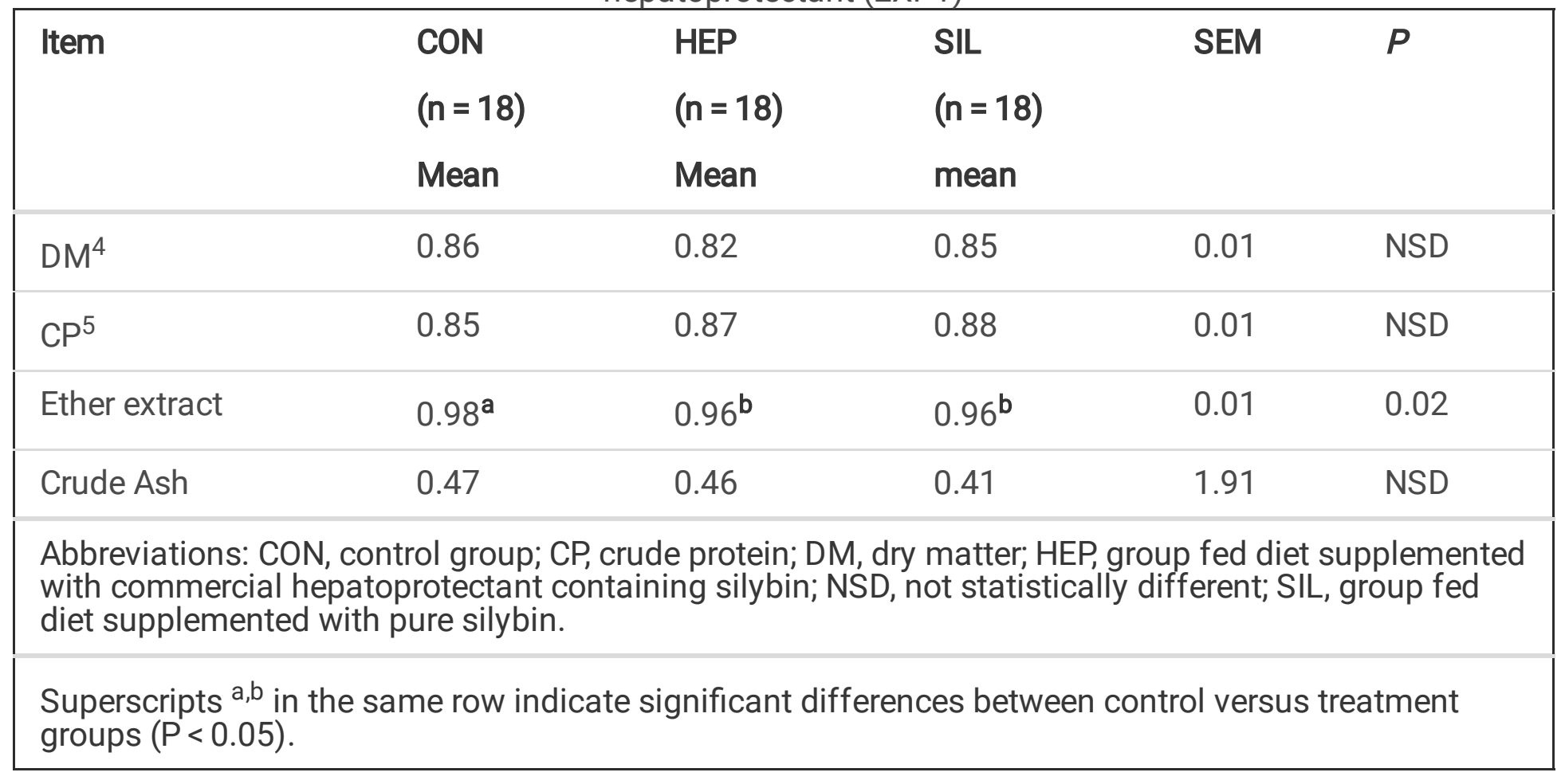

\section{Hematology and serum biochemistry: EXP1}

SIL and HEP had an effect on hematological parameters (Table 4). WBC was lower in the treatment groups than in the CON group. Monocyte and eosinophil counts were lower in the HEP group than in the 
CON and SIL groups. Neutrophil count was higher in the CON group than in the HEP and SIL groups. RBC, hemoglobin, and hematocrit were not statistically significant, and no significant differences were seen in $\mathrm{MCV}, \mathrm{MCH}, \mathrm{MCHC}$, or PLT between the CON and treatment groups during EXP1. All hematological parameters were within their reference ranges and supplementation did not adversely affect them.

We noted that albumin, alpha-amylase, and AP-alkaline phosphatase were significantly lower in the CON group than in the HEP and SIL groups (Table 4). On the other hand, total bilirubin was higher in the HEP group than in the CON group. Finally, the serum activity of GGT was significantly higher in the treatment groups than in the CON group.

Considering carbohydrates metabolism, we observed fructosamine to be higher in the HEP group than in the CON group. Further, glucose concentration was higher in CON than in the treatment groups (Table 4). Additionally, taking into account lipid metabolism, triglyceride concentration was higher in the treatment groups than in the CON group.

lonograms revealed that $\mathrm{Mg}^{2+}$ and $\mathrm{K}^{+}$concentrations were higher in the treatment groups than in CON. The calcium concentration was however lower in the HEP group than in the CON group. Precise results are given in Table 4. 
Table 4

Hematology and serum biochemistry of dogs fed diets supplemented with silybin and commercial hepatoprotectant (EXP1)

\begin{tabular}{|c|c|c|c|c|c|}
\hline Item & $\begin{array}{l}\text { CON } \\
(n=18)\end{array}$ & $\begin{array}{l}\text { HEP } \\
(n=18)\end{array}$ & $\begin{array}{l}\text { SIL } \\
(n=18)\end{array}$ & SEM & $P$ \\
\hline & Mean & mean & Mean & & \\
\hline WBC $\left(\times 10^{9} / \mathrm{L}\right)$ & $10.5^{a}$ & $8.84^{b}$ & $9.02^{b}$ & 0.28 & 0.02 \\
\hline NEUT $\left(\times 10^{9} / \mathrm{L}\right)$ & $6.99^{a}$ & $5.51^{\mathrm{b}}$ & $5.37^{b}$ & 0.25 & 0.01 \\
\hline $\operatorname{LYM}\left(\times 10^{9} / \mathrm{L}\right)$ & 2.15 & 2.50 & 2.58 & 0.08 & NSD \\
\hline MONO $\left(\times 10^{9} / \mathrm{L}\right)$ & $0.90^{\mathrm{a}}$ & $0.65^{b}$ & $.74^{\mathrm{ab}}$ & 0.04 & 0.03 \\
\hline $\operatorname{EOS}\left(\times 10^{9} / \mathrm{L}\right)$ & $0.45^{a}$ & $0.15^{b}$ & $.29^{a b}$ & 0.05 & 0.03 \\
\hline BASO $\left(\times 10^{9} / \mathrm{L}\right)$ & 0.04 & 0.04 & .03 & 0.00 & NSD \\
\hline $\mathrm{RBC}\left(\times 10^{12} / \mathrm{L}\right)$ & 6.81 & 6.79 & 6.92 & 0.08 & NSD \\
\hline HEM (g/L) & 160 & 164 & 166 & 1.74 & NSD \\
\hline HTC (\%) & 0.46 & 0.47 & 0.47 & 0.01 & NSD \\
\hline MCV (fL/cell) & 67.9 & 68.7 & 68.5 & 0.34 & NSD \\
\hline $\mathrm{MCH}$ (pg/cell) & $23.5^{b}$ & $24.1^{a}$ & $24.0^{\mathrm{a}}$ & 0.08 & 0.001 \\
\hline $\mathrm{MCHC}(\mathrm{g} / \mathrm{L})$ & 346 & 352 & 350 & 1.49 & NSD \\
\hline $\operatorname{PLT}\left(\times 10^{9} / \mathrm{L}\right)$ & 219 & 245 & 241 & 8.82 & NSD \\
\hline Albumin (g/L) & 3.7 & 3.6 & 31.0 & 0.31 & NSD \\
\hline $\operatorname{ALT}(\mathrm{U} / \mathrm{L})$ & 37.7 & 39.0 & 36.1 & 1.36 & NSD \\
\hline Alpha-Amylase (U/L) & $752^{a}$ & $467^{b}$ & $593^{b}$ & 31.8 & $<0.001$ \\
\hline
\end{tabular}

Abbreviations: CON, control group; HEP, group fed diet supplemented with commercial hepatoprotectant containing silybin; SIL, group fed diet supplemented with pure silybin; WBC, White blood cells; NEUT, neutrophils; LYM, lymphocytes; MONO, monocytes; EOS, eosinophils; BASO, basophils; RBC, red blood cells; HEM, hemoglobin; HTC, hematocrit; MCV, mean corpuscular volume; $\mathrm{MCHC}$, mean corpuscular hemoglobin concentration; PLT, platelets; ALT, alanine aminotransferase; ALP, alkaline phosphatase; AST, aspartate aminotransferase; CK, creatinine kinase; GLDH, glutamate dehydrogenase; GLUC, glucose; GGT, gamma glutamyl transpeptidase; LDH, lactic dehydrogenase; TG, triglycerides; NSD, not statistically different.

Superscripts ${ }^{a, b}$ in the same row indicate significant differences between control versus treatment groups $(p<0.05)$. 


\begin{tabular}{|c|c|c|c|c|c|}
\hline \multirow[t]{2}{*}{ Item } & $\begin{array}{l}\text { CON } \\
(n=18)\end{array}$ & $\begin{array}{l}\text { HEP } \\
(n=18)\end{array}$ & $\begin{array}{l}\text { SIL } \\
(n=18)\end{array}$ & \multirow[t]{2}{*}{ SEM } & \multirow[t]{2}{*}{$P$} \\
\hline & Mean & mean & Mean & & \\
\hline $\operatorname{ALP}(\mathrm{U} / \mathrm{L})$ & $42.6^{\mathrm{a}}$ & $35.4^{\mathrm{b}}$ & $31.2^{b}$ & 1.29 & $<0.001$ \\
\hline AST (U/L) & 28.6 & 32.6 & 32.2 & 0.89 & NSD \\
\hline Total protein (g/L) & 58.2 & 59.6 & 59.4 & 0.55 & NSD \\
\hline Total bilirubin $(\mu \mathrm{mol} / \mathrm{l})$ & $2.94^{b}$ & $3.39^{a}$ & $3.03^{\mathrm{ab}}$ & 0.07 & 0.04 \\
\hline Cholesterol (mmol/L) & 4.28 & 4.61 & 4.69 & 0.12 & NSD \\
\hline CK (U/L) & 152 & 154 & 154 & 5.71 & NSD \\
\hline Fructosamine $(\mu \mathrm{mol} / \mathrm{l})$ & $242^{b}$ & $265^{a}$ & $258^{a b}$ & 3.32 & 0.01 \\
\hline GLDH (U/L) & 2.98 & 3.40 & 3.27 & 0.09 & NSD \\
\hline GLUC (mmol/L) & $6.18^{\mathrm{a}}$ & $5.09^{b}$ & $5.42^{\mathrm{b}}$ & 0.11 & $<0.001$ \\
\hline GGT (U/L) & $2.30^{\mathrm{b}}$ & $4.08^{a}$ & $3.32^{\mathrm{a}}$ & 0.20 & $<0.001$ \\
\hline Creatinine $(\mu \mathrm{mol} / \mathrm{l})$ & 71.8 & 67.5 & 68.0 & 1.64 & NSD \\
\hline LDH (U/L) & 157 & 141.1 & 146 & 12.3 & NSD \\
\hline Lipase (DGGR) (U/L) & 58.8 & 68.0 & 76.5 & 3.41 & NSD \\
\hline Urea (mmol/L) & 3.98 & 4.60 & 4.48 & 0.15 & NSD \\
\hline TG (mmol/L) & $0.42^{b}$ & $0.59^{a}$ & $0.54^{\mathrm{a}}$ & 0.02 & $<0.001$ \\
\hline Chloride (mmol/L) & 114 & 112 & 113 & 0.34 & NSD \\
\hline Inorganic phosphorus (mmol/L) & 1.31 & 1.52 & 1.52 & 0.05 & NSD \\
\hline Magnesium (mmol/L) & $0.70^{\mathrm{b}}$ & $0.79^{a}$ & $0.80^{\mathrm{a}}$ & 0.01 & $<0.001$ \\
\hline Potassium (mmol/L) & $4.17^{b}$ & $4.52^{\mathrm{a}}$ & $4.54^{\mathrm{a}}$ & 0.05 & $<0.001$ \\
\hline \multicolumn{6}{|c|}{$\begin{array}{l}\text { Abbreviations: CON, control group; HEP, group fed diet supplemented with commercial } \\
\text { hepatoprotectant containing silybin; SIL, group fed diet supplemented with pure silybin; WBC, White } \\
\text { blood cells; NEUT, neutrophils; LYM, lymphocytes; MONO, monocytes; EOS, eosinophils; BASO, } \\
\text { basophils; RBC, red blood cells; HEM, hemoglobin; HTC, hematocrit; MCV, mean corpuscular volume; } \\
\text { MCHC, mean corpuscular hemoglobin concentration; PLT, platelets; ALT, alanine aminotransferase; } \\
\text { ALP, alkaline phosphatase; AST, aspartate aminotransferase; CK, creatinine kinase; GLDH, glutamate } \\
\text { dehydrogenase; GLUC, glucose; GGT, gamma glutamyl transpeptidase; LDH, lactic dehydrogenase; } \\
\text { TG, triglycerides; NSD, not statistically different. }\end{array}$} \\
\hline
\end{tabular}




\begin{tabular}{|c|c|c|c|c|c|}
\hline \multirow[t]{2}{*}{ Item } & $\begin{array}{l}\text { CON } \\
(n=18)\end{array}$ & $\begin{array}{l}\text { HEP } \\
(n=18)\end{array}$ & $\begin{array}{l}\text { SIL } \\
(n=18)\end{array}$ & SEM & $P$ \\
\hline & Mean & mean & Mean & & \\
\hline Sodium (mmol/L) & 148 & 146 & 147 & 0.37 & 0.05 \\
\hline Calcium (mmol/L) & $2.56^{\mathrm{a}}$ & $2.44^{b}$ & $2.50^{\mathrm{ab}}$ & 0.02 & 0.001 \\
\hline Albumin / globulin ratio & 1.12 & 1.07 & 1.11 & 0.03 & NSD \\
\hline Globulin (g/L) & 27.5 & 29.0 & 28.4 & 0.59 & NSD \\
\hline \multicolumn{6}{|c|}{$\begin{array}{l}\text { Abbreviations: CON, control group; HEP, group fed diet supplemented with commercial } \\
\text { hepatoprotectant containing silybin; SIL, group fed diet supplemented with pure silybin; WBC, White } \\
\text { blood cells; NEUT, neutrophils; LYM, lymphocytes; MONO, monocytes; EOS, eosinophils; BASO, } \\
\text { basophils; RBC, red blood cells; HEM, hemoglobin; HTC, hematocrit; MCV, mean corpuscular volume; } \\
\text { MCHC, mean corpuscular hemoglobin concentration; PLT, platelets; ALT, alanine aminotransferase; } \\
\text { ALP, alkaline phosphatase; AST, aspartate aminotransferase; CK, creatinine kinase; GLDH, glutamate } \\
\text { dehydrogenase; GLUC, glucose; GGT, gamma glutamyl transpeptidase; LDH, lactic dehydrogenase; } \\
\text { TG, triglycerides; NSD, not statistically different. }\end{array}$} \\
\hline \multicolumn{6}{|c|}{$\begin{array}{l}\text { Superscripts }{ }^{a, b} \text { in the same row indicate significant differences between control versus treatment } \\
\text { groups }(p<0.05) .\end{array}$} \\
\hline
\end{tabular}

\section{Serum fatty acid profile: EXP1}

Supplementation did not affect the serum fatty acid profile of dogs, with the exception of C20:5 n3, the concentration of which was lower in the treatment groups than in the CON group (Table 5). 
Table 5

Serum fatty acid profile of dogs fed diets supplemented with silybin and commercial hepatoprotectant (EXP1)

\section{$\mathrm{FA}(\mathrm{g} / 100 \mathrm{~g} \mathrm{FA})$}

\begin{tabular}{|c|c|c|c|c|c|}
\hline & $\begin{array}{l}\text { CON } \\
(n=18)\end{array}$ & $\begin{array}{l}\text { HEP } \\
(n=18)\end{array}$ & $\begin{array}{l}\text { SIL } \\
(n=18)\end{array}$ & SEM & $P$ \\
\hline & mean & Mean & Mean & & \\
\hline C14:0 & 0.25 & 0.20 & 0.24 & 0.01 & NSD \\
\hline C15:0 & $0.08^{b}$ & $0.13^{a}$ & $0.10^{\mathrm{ab}}$ & 0.01 & 0.02 \\
\hline $\mathrm{C} 16: 0$ & 11.4 & 11.5 & 1.8 & 0.24 & NSD \\
\hline C17:0 & $0.30^{b}$ & $0.39^{a}$ & $0.34^{\mathrm{ab}}$ & 0.01 & 0.04 \\
\hline C18:0 & 17.2 & 17.7 & 18.4 & 0.25 & NSD \\
\hline $\mathrm{C} 20: 0$ & 0.18 & 0.22 & 0.19 & 0.01 & NSD \\
\hline $\mathrm{C} 22: 0$ & $1.27^{\mathrm{a}}$ & $0.84^{b}$ & $1.11^{a}$ & 0.06 & $<0.001$ \\
\hline $\mathrm{C} 23: 0$ & 0.01 & 0.01 & 0.01 & 0.001 & NSD \\
\hline $\mathrm{C} 24: 0$ & 0.03 & 0.03 & 0.03 & 0.001 & NSD \\
\hline C14:1 & 0.04 & 0.04 & 0.03 & 0.001 & NSD \\
\hline C15:1 & 0.12 & 0.12 & 0.11 & 0.01 & NSD \\
\hline C16:1 & 1.15 & 1.33 & 1.19 & 0.08 & NSD \\
\hline C17:1 & 0.16 & 0.14 & 0.14 & 0.01 & NSD \\
\hline C18:1 t9 & 0.11 & 0.10 & 0.12 & 0.01 & NSD \\
\hline C18:1 t11 & 0.28 & 0.29 & 0.32 & 0.01 & NSD \\
\hline C18:1 cis 9 & 11.4 & 11.2 & 11.4 & 0.42 & NSD \\
\hline C20:1 trans & 0.06 & 0.06 & 0.07 & 0.01 & NSD \\
\hline $\mathrm{C} 22: 1 \mathrm{n} 9$ & 0.33 & 0.24 & 0.30 & 0.02 & NSD \\
\hline
\end{tabular}

Abbreviations: CON, control group; HEP, group fed diet supplemented with commercial hepatoprotectant containing silybin; SIL, group fed diet supplemented with pure silybin; SFA, saturated fatty acids; UFA, unsaturated fatty acids; MUFA, monounsaturated fatty acids; PUFA, polyunsaturated fatty acids; MCFA, medium chain fatty acids; LCFA, long chain fatty acids; NSD, not statistically different.

Superscripts ${ }^{a, b}$ in the same row indicate significant differences between control versus treatment groups $(p<0.05)$. 
$F A(g / 100 \mathrm{~g} \mathrm{FA})$

\begin{tabular}{|c|c|c|c|c|c|}
\hline & & & & & \\
\hline & CON & & & SEM & $P$ \\
\hline & $(n=18)$ & $(n=18)$ & $(n=18)$ & & \\
\hline & mean & Mean & Mean & & \\
\hline $\mathrm{C} 18: 2$ c 9 c 12 & 25.7 & 27.4 & 27.2 & 0.47 & NSD \\
\hline $\mathrm{C} 18: 3$ c 9 c12 c15 & 0.64 & 0.79 & 0.83 & 0.04 & NSD \\
\hline $\mathrm{C} 18: 3 \mathrm{n} 6$ & 0.04 & 0.04 & 0.05 & 0.001 & NSD \\
\hline $\mathrm{C} 20: 2$ & 0.16 & 0.14 & 0.16 & 0.01 & NSD \\
\hline $\mathrm{C} 20: 3 \mathrm{n} 6$ & 19.0 & 17.7 & 16.8 & 0.50 & NSD \\
\hline $\mathrm{C} 20: 4 \mathrm{n} 6$ & 0.02 & 0.02 & 0.02 & 0.001 & NSD \\
\hline C20:5 n3 & $0.99^{a}$ & $0.58^{b}$ & $0.54^{b}$ & 0.06 & $<0.001$ \\
\hline $\mathrm{C} 22: 5 \mathrm{n} 3$ & 2.01 & 2.72 & 2.30 & 0.13 & NSD \\
\hline $\mathrm{C} 22: 6 \mathrm{n} 3$ & 0.04 & 0.04 & 0.04 & 0.01 & NSD \\
\hline Others & 9.79 & 8.09 & 9.30 & - & - \\
\hline SUM & 100 & 100 & 100 & - & - \\
\hline${ }^{1}$ SFA & 31.6 & $31.5(1.30)$ & $32.6(2.10)$ & 0.43 & NSD \\
\hline${ }^{2} \mathrm{UFA}$ & 68.4 & $68.5(1.30)$ & $67.4(2.10)$ & 0.43 & NSD \\
\hline${ }^{3}$ MUFA & 19.7 & $18.9(.96)$ & $19.2(1.15)$ & 0.45 & NSD \\
\hline${ }^{4}$ PUFA & 48.5 & 49.4 & 48.0 & 0.71 & NSD \\
\hline$n-6$ & 45.0 & 45.3 & 44.4 & 0.63 & NSD \\
\hline$n-3$ & 3.68 & 4.12 & 3.71 & 0.13 & NSD \\
\hline n6/n3 & 12.4 & 11.0 & 12.3 & 0.37 & NSD \\
\hline n6 PUFA & 44.7 & 45.2 & 44.1 & 0.63 & NSD \\
\hline
\end{tabular}

Abbreviations: CON, control group; HEP, group fed diet supplemented with commercial hepatoprotectant containing silybin; SIL, group fed diet supplemented with pure silybin; SFA, saturated fatty acids; UFA, unsaturated fatty acids; MUFA, monounsaturated fatty acids; PUFA, polyunsaturated fatty acids; MCFA, medium chain fatty acids; LCFA, long chain fatty acids; NSD, not statistically different.

Superscripts ${ }^{a, b}$ in the same row indicate significant differences between control versus treatment groups $(p<0.05)$. 


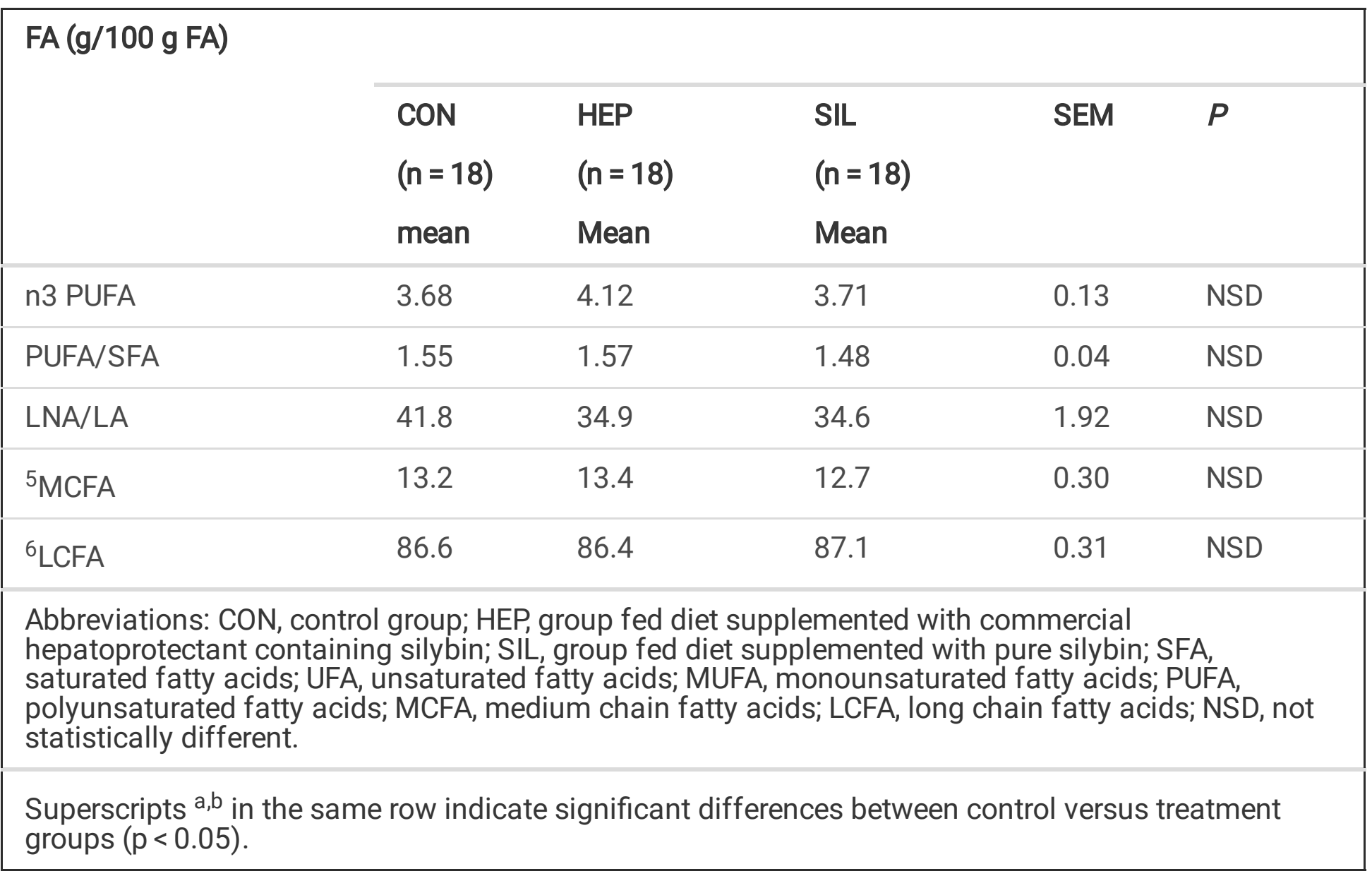

\section{Serum cytokines, immunoglobulins, and acute phase proteins: EXP1}

The supplementation had no significant effect on inflammatory proteins, but IL4 concentration was significantly higher in the treatment groups than in the CON group (Table 6). IL10 concentration was higher in the SIL group than in the CON group. 
Table 6

Serum Interleukins, immunoglobulins, and acute phase proteins in dogs fed diets supplemented with silybin and commercial hepatoprotectant (EXP1)

\begin{tabular}{|c|c|c|c|c|c|c|}
\hline Item & Unit & $\begin{array}{l}\text { CON } \\
(n=18)\end{array}$ & $\begin{array}{l}\text { HEP } \\
(n=18)\end{array}$ & $\begin{array}{l}\text { SIL } \\
(n=18)\end{array}$ & SEM & $P$ \\
\hline $1 \mathrm{~L}-\beta$ & $(\mathrm{pg} / \mathrm{ml})$ & 10.3 & 13.5 & 14.2 & 3.41 & NSD \\
\hline IL4 & $(\mathrm{pg} / \mathrm{ml})$ & $382^{b}$ & $494^{a}$ & $478^{a}$ & 17.5 & $<0.01$ \\
\hline IL6 & $(\mathrm{pg} / \mathrm{ml})$ & 9409 & 9042 & 8659 & 322.1 & NSD \\
\hline IL8 & $(\mathrm{pg} / \mathrm{ml})$ & 22.8 & 114.0 & 52.6 & 29.0 & NSD \\
\hline IL10 & $(\mathrm{pg} / \mathrm{ml})$ & $12.2^{b}$ & $19.8^{a b}$ & $25.3^{a}$ & 1.6 & $<0.01$ \\
\hline $\lg A$ & $(\mathrm{mg} / \mathrm{ml})$ & 0.805 & 0.744 & 0.769 & 0.25 & NSD \\
\hline $\lg G$ & $(\mathrm{mg} / \mathrm{ml})$ & 9.2 & 10.3 & 10.1 & 0.51 & NSD \\
\hline $\lg M$ & $(\mathrm{mg} / \mathrm{ml})$ & 1.397 & 1.393 & 1.441 & 0.042 & NSD \\
\hline $\lg \mathrm{E}$ & $(\mu \mathrm{g} / \mathrm{ml})$ & 1.794 & .885 & 2.565 & 0.18 & NSD \\
\hline Haptoglobin & $(\mathrm{mg} / \mathrm{ml})$ & 0.04 & 0.02 & 0.06 & 0.01 & NSD \\
\hline CRP & $(\mathrm{ng} / \mathrm{ml})$ & 624 & 505 & 681 & 40 & NSD \\
\hline SAA & $(\mu \mathrm{g} / \mathrm{ml})$ & 18.8 & 16.1 & 15.8 & 3.70 & NSD \\
\hline \multicolumn{7}{|c|}{$\begin{array}{l}\text { Abbreviations: CON, control group; HEP, group fed diet supplemented with commercial } \\
\text { hepatoprotectant containing silybin; SIL, group fed diet supplemented with pure silybin; CRP, C- } \\
\text { reactive protein; NSD, not statistically different; SA, serum amyloid-A. }\end{array}$} \\
\hline
\end{tabular}

\section{Urine cortisol to creatinine ratio: EXP1}

Supplementation did not affect urine $\mathrm{pH}$, cortisol concentration, or creatinine concentration. Thus, the cortisol:creatinine ratio was not affected either (Table 7). 
Table 7

The urine cortisol/creatinine ratio of dogs fed diets supplemented with silybin and commercial hepatoprotectant (EXP1)

\begin{tabular}{|c|c|c|c|c|c|c|}
\hline Item & Unit & $\begin{array}{l}\text { CON } \\
(n=18) \\
\text { mean }\end{array}$ & $\begin{array}{l}\text { HEP } \\
(n=18) \\
\text { Mean }\end{array}$ & $\begin{array}{l}\text { SIL } \\
(n=18) \\
\text { mean }\end{array}$ & SEM & $P$ \\
\hline $\mathrm{pH}$ & & 7.56 & 6.88 & 7.00 & 0.21 & NSD \\
\hline Cortisol & $\mu \mathrm{g} / \mathrm{dl}$ & 13.5 & 13.7 & 13.4 & 0.11 & NSD \\
\hline Creatinine & $\mu \mathrm{mol} / \mathrm{l}$ & 16419 & 14431 & 12907 & 1017 & NSD \\
\hline Cortisol: creatinine & $10^{-6}$ & 29.4 & 26.5 & 28.2 & 0.85 & NSD \\
\hline
\end{tabular}

\section{Hematology and serum biochemistry: EXP 2}

Supplementation did not affect hematological parameters in the dogs with hepatopathies, and liver markers such as ALT, AST, and GGT significantly decreased (Table 8). 
Table 8

Hematology and serum biochemistry of dogs with liver disorders fed diet supplemented with commercial hepatoprotectant containing silybin (EXP2)

\begin{tabular}{|c|c|c|c|c|c|}
\hline Item & Reference value & $\begin{array}{l}\mathrm{H} 1 \\
\mathrm{n}=15\end{array}$ & $\begin{array}{l}H 28 \\
n=15\end{array}$ & SEM & $P$ \\
\hline WBC $\left(\times 10^{9} / \mathrm{L}\right)$ & $6.00-12.0$ & 11.40 & 14.00 & 1.890 & NSD \\
\hline NEUT $\left(\times 10^{9} / \mathrm{L}\right)$ & $3.00-9.00$ & 7.59 & 9.87 & 1.752 & NSD \\
\hline $\operatorname{LYM}\left(\times 10^{9} / \mathrm{L}\right)$ & $1.00-3.60$ & 2.60 & 2.37 & 0.362 & NSD \\
\hline MONO $\left(\times 10^{9} / \mathrm{L}\right)$ & $0.150-0.850$ & 0.77 & 1.21 & 0.158 & NSD \\
\hline $\operatorname{EOS}\left(\times 10^{9} / \mathrm{L}\right)$ & $0.040-0.600$ & 0.42 & 0.50 & 0.068 & NSD \\
\hline $\operatorname{BASO}\left(\times 10^{9} / \mathrm{L}\right)$ & $0.001-0.100$ & 0.02 & 0.05 & 0.006 & 0.005 \\
\hline $\operatorname{RBC}\left(\times 10^{12} / \mathrm{L}\right)$ & $5.50-8.50$ & 7.03 & 6.61 & 0.511 & NSD \\
\hline HEM (g/L) & $15.0-19.0$ & 175.80 & 127.50 & 11.659 & NSD \\
\hline HTC (\%) & $0.440-0.550$ & 1.66 & 0.41 & 6.919 & NSD \\
\hline MCV (fL/cell) & $6.0-77.0$ & 71.14 & 63.95 & 2.255 & NSD \\
\hline $\mathrm{MCH}$ (pg/cell) & $21.0-27.0$ & 24.92 & 2.55 & 1.170 & NSD \\
\hline $\mathrm{MCHC}(\mathrm{g} / \mathrm{L})$ & $32.0-36.0$ & 35.20 & 319.00 & 7.141 & NSD \\
\hline $\operatorname{PLT}\left(\times 10^{9} / \mathrm{L}\right)$ & $15.0-50.0$ & 204.80 & 154.00 & 8.354 & NSD \\
\hline Albumin $(\mathrm{g} / \mathrm{L})$ & $25.0-44.0$ & 37.71 & 33.50 & 1.160 & 0.046 \\
\hline ALT (U/L) & $1.00-8.0$ & 325.44 & 195.35 & 103.233 & 0.012 \\
\hline $\operatorname{ALP}(\mathrm{U} / \mathrm{L})$ & $1.00-141.0$ & 83.25 & 153.10 & 39.726 & NSD \\
\hline AST (U/L) & $1.00-76.0$ & 35.03 & 24.09 & 4.879 & 0.016 \\
\hline Total protein $(\mathrm{g} / \mathrm{L})$ & $54.0-75.0$ & 65.18 & 58.60 & 2.535 & NSD \\
\hline Total bilirubin $(\mu \mathrm{mol} / \mathrm{L})$ & $0.010-4.60$ & 3.22 & 3.99 & 0.212 & 0.037 \\
\hline Fructosamine $(\mu \mathrm{mol} / \mathrm{L})$ & $225.0-365.0$ & 28.93 & 188.0 & 18.167 & 0.035 \\
\hline
\end{tabular}

Abbreviations: $\mathrm{H} 1$, first day of supplementation; $\mathrm{H} 28$, twenty-eighth day of supplementation; WBC, White blood cells; NEUT, neutrophils; LYM, lymphocytes; MONO, monocytes; EOS, eosinophils; BASO, basophils; RBC, red blood cells; HEM, hemoglobin; HTC, hematocrit; MCV, mean corpuscular volume; $\mathrm{MCH}$, mean corpuscular hemoglobin MCHC, mean corpuscular hemoglobin concentration; PLT, platelets; ALT, alanine aminotransferase; ALP, alkaline phosphatase; AST, aspartate aminotransferase; GLDH, glutamate dehydrogenase; GLUC, glucose; GGT, gamma glutamyl transpeptidase; NSD, not statistically different. 


\begin{tabular}{|c|c|c|c|c|c|}
\hline Item & Reference value & $\begin{array}{l}H 1 \\
n=15\end{array}$ & \multicolumn{3}{|l|}{$n=15$} \\
\hline GLDH (U/L) & $0.010-1.6$ & 22.82 & 13.32 & 4.824 & 0.053 \\
\hline GLUC (mmol/L) & $3.05-6.10$ & 5.78 & 5.16 & 0.325 & NSD \\
\hline GGT (U/L) & $0.010-7.00$ & 23.58 & 7.34 & 7.535 & 0.027 \\
\hline Creatinine $(\mu \mathrm{mol} / \mathrm{L})$ & $35.0-132.0$ & 97.51 & 77.65 & 7.163 & NSD \\
\hline Urea (mmol/L) & $3.30-8.30$ & 7.42 & 3.72 & 0.977 & 0.045 \\
\hline Albumin / globulin ratio & $0.670-1.60$ & 1.09 & 0.83 & 0.081 & NSD \\
\hline Globulin (g/L) & $18.0-45.0$ & 31.39 & 36.25 & 1.807 & 0.008 \\
\hline L- amylase (g/L) & $10-1650$ & 3.77 & 33.50 & 1.16 & 0.050 \\
\hline \multicolumn{6}{|c|}{$\begin{array}{l}\text { Abbreviations: H1, first day of supplementation; H28, twenty-eighth day of supplementation; WBC, } \\
\text { White blood cells; NEUT, neutrophils; LYM, Iymphocytes; MONO, monocytes; EOS, eosinophils; BASO, } \\
\text { basophils; RBC, red blood cells; HEM, hemoglobin; HTC, hematocrit; MCV, mean corpuscular volume; } \\
\text { MCH, mean corpuscular hemoglobin MCHC, mean corpuscular hemoglobin concentration; PLT, } \\
\text { platelets; ALT, alanine aminotransferase; ALP, alkaline phosphatase; AST, aspartate aminotransferase; } \\
\text { GLDH, glutamate dehydrogenase; GLUC, glucose; GGT, gamma glutamyl transpeptidase; NSD, not } \\
\text { statistically different. }\end{array}$} \\
\hline
\end{tabular}

\section{Serum microRNA expression: EXP1}

We did not observe any differences between the effects of silybin and commercial hepatoprotectant on miRNA expression in healthy dogs (Fig. 1), but we did find that 28-day supplementation with commercial hepatoprotectant significantly decreased the expression level of miR-122 and miR-126. We did not observe any effect of the commercial hepatoprotectant on miR-192 (Fig. 2).

\section{Discussion}

Liver disorders are a significant group of pathologies in dogs. Patients with hepatopathies are nutritionally demanding and should be provided with high-quality feed supplemented with additives that exhibit liver-beneficial properties and do not interfere with digestion. It is worth mentioning that the presence of antinutritional factors in pet food is important and may lower the digestibility of dogs' diets [18]. Generally, our study (in EXP1) suggests that silybin-the active substance in silymarin-does not interfere with digestion processes. The slightly lower ether extract digestibility in the experimental groups might be due to a slight laxative effect [19] or to the occurrence of subclinical gastroenteritis, which has been reported as a rare adverse effect of silymarin [20]. However, no signs of diarrhoea were observed in the experimental groups. On the other hand, silybin has cholagogic properties, so we might expect lipid digestion to be enhanced [21]. To our knowledge, no experiments have investigated the effects of silybin 
on nutrient digestibility in dogs. The literature does, however, discuss these effects in other animals: One report suggests that Silybum marianum (L.) as source of silymarin has no effect on nutrient digestibility in buffalos [22], while an experiment with broiler chickens incorporating $S$. marianum seeds into the diet resulted in increased nutrient digestibility in terms of mycotoxin-contaminated feed [23]. The present study found no clinically significant differences in hematological parameters between the groups of dogs. Likewise, Chon and Kim [24] observed no significant differences in hematological parameters such as WBC, $\mathrm{RBC}, \mathrm{MCV}, \mathrm{MCH}$, or $\mathrm{MCHC}$ between the control group and the group treated with silybin in the case of giardiasis in dogs. Liver enzymes activity significantly decreased in experimental groups (both SIL and HEP), as in other studies with various liver-associated dysfunctions [25-27]. Our study shows that, in healthy dogs, liver performance is not negatively affected by silybin supplementation. On the other hand, some reports describe a prophylactic effect of silymarin containing silybin in cats [28] and rats [29]. For example, silymarin protected the liver in healthy cats given acetaminophen. ALT/GPT, AST/GOT, ALP, and LDH did not increase, as happened in cats given acetaminophen alone [30]. It is important to highlight that poisoning with nonsteroidal anti-inflammatory drugs (NSAIDs) happens relatively often in small animal practice, as a result of unauthorised administration by the owner. Nevertheless, it should be kept in mind that elevated hepatic markers are not always associated with liver injury: they could be a transient effect of the administration of drugs such as phenobarbital in epileptic dogs [31] or glucocorticoids [32]. The literature even describes congenital breed-related causes of elevated liver markers, like benign familial hyperphosphatasemia in Siberian huskies or increased ALP activity in Scottish terriers (where it may be as much as five times higher than in other breeds) [32]. The supplementation of both HEP and SIL slightly altered the serum fatty acid profile. These, statistically significant, changes were seen in the small amounts of fatty acids physiologically present in serum, and are not clinically relevant. The increase in concentration of $\mathrm{C} 15: 0$ and $\mathrm{C} 17: 0$ and the subsequent decrease in C20:5 n-3 may be associated with a moderate interference with lipid metabolism [33], as discussed later. To our knowledge, there are no studies to have investigated changes in the quality of the serum fatty acid profile in animals supplemented with silybin. In our study, supplementation with HEP and SIL did not affect serum cholesterol concentration, but triglyceride concentration increased. This does not agree with the study of Sun [34], who showed that in a mouse model with nonalcoholic fatty liver syndrome, silybin supplementation significantly lowered both serum and hepatic lipid accumulation. Similar results were obtained by Ramakrishnan in rats [35] with induced hepatocellular carcinoma. Moreover, the combination of silymarin and $n-3$ fatty acid supplementation may enhance the antihyperlipidemic effect in rats with metabolic syndrome [36]. These discrepancies with our results are probably due to the fact that different breeds and animals with induced liver disorders were used, rather than the healthy animals in our study (EXP1).

Silymarin, the source of silybin, is believed to protect against renal injury by normalizing the lipid metabolism [37]. Our study suggests that supplementation had no effect on the urine parameters, and thus on the renal function, in healthy dogs (EXP1). Silymarin is eliminated mainly by bile [38], and it does not alter urine $\mathrm{pH}$, which is a significant feature in terms of urolith formation and the diagnosis of diseases (such as diabetes mellitus) by urinalysis, as it does not conceal the symptoms. Moreover, since 
the excretion of some drugs (such as phenobarbital or gentamycin) is related to urine $\mathrm{pH}$ [39], the lack of effect of both the commercial preparation and the pure silybin supplementation on urine $\mathrm{pH}$ seems to be advantageous.

Silymarin displays anti-inflammatory effects on T-lymphocytes in vitro [40-42]. The immunomodulatory properties of oral silymarin (silybin) in vivo in dogs have not previously been described. This study found that neither pure silybin nor commercial hepatoprotectant affected most of the immunological and inflammatory parameters. The supplementation had significant effect only on IL 4 and IL10 concentration in serum. Immunoregulatory cytokines such as IL4 and IL10 have been described as exerting antiinflammatory properties on various cell types [43-45]. The IL4 level was significantly higher in the treatment groups than in the CON group, while IL10 concentration was higher in the SIL group than in the CON group. Previous studies involving human subjects have demonstrated a significant relationship between greater hepatic inflammation and subsequent fibrosis progression [46, 47]. Thus, control of inflammation may be a useful strategy for ameliorating the sequelae of chronic liver disease. Here we have demonstrated that silybin has the ability to increase anti-inflammatory cytokine concentration in serum and has no effect on the proinflammatory cytokine secretion in vivo, which can be considered a positive effect. Silybin administration in dogs has been well documented as an effective therapeutical tool for different types of liver injuries, such as induced toxaemia, drug poisoning, chemotherapy, and chronic hepatitis [48, 26-28]. Several reports also describe its antiviral and antineoplastic properties in laboratory animals or cell cultures $[35,49,50]$. Similarly, in the current study, silybin supplementation improved liver performance regardless of the underlying hepatic disease. We consequently observed a significant decrease in liver enzymatic markers in dogs with liver disorders (EXP2).

In recent years, in addition to traditional markers for liver diseases, such as ALT, AST, ALP and GGT, genetic markers are increasingly used, including changes in the level of microRNA [51-53]. Previous studies have shown that miR-122 and miR-126 are highly specific for the liver in dogs [52, 54-55], while miR-192 is less specific for the liver in dogs. However, in vitro research on mice has also shown that pathological changes accompanying liver damage may be reflected in miR-192 expression [56]. We therefore decided to examine these three types of miRNA as potential markers for liver metabolism. In EXP1, we investigated whether the administration of SIL and HEP affected the liver metabolism of healthy dogs; since this study showed no negative impact, we decided to investigate the effect of HEP on animals with hepatic disorders. In EXP2, we found that HEP decreased the relative expression of miR-122 after 28 days of supplementation, and also downregulated miR-126; however, in case of miR-126, only a slight trend was observed ( $\mathrm{H} 1 \mathrm{vs}$. $\mathrm{H} 28)$, and it was not statistically significant $(\mathrm{P}=0.241)$.

The usefulness of miRNAs in the diagnosis of liver diseases has been confirmed by data in the literature which show that increased miR-122 expression is noted in almost all liver diseases in dogs, such as acute and chronic hepatitis, hepatocellular carcinoma, lymphoma, and other biliary diseases like extrahepatic bile duct obstruction [51]. These results have also been confirmed by Oosthuyzen et al. [55], who showed that changes in this parameter are not associated with the breed, age, or sex of the dog, and that the number of miR-122 copies increases only during the occurrence of liver disease. They moreover

Page 18/32 
demonstrated a positive correlation between miR-122 and ALT, which is one of the main markers used in the diagnosis of liver diseases [55]. Based on our results in EXP2, and due to the low specificity of changes in miR-122 in relation to various liver diseases (as shown by Dirksen et al. in 2016), we can only conclude that the metabolism of this organ improved [51].

The second type of miRNA investigated in our study was miR-126. Although only minor changes were observed for the HEP group ( $\mathrm{H} 1 \mathrm{vs.} \mathrm{H} 28$ ), we decided to study this type of miRNA only because other studies on humans have indicated that miR-126 could also be used as a liver disease marker [56]. This was also indirectly confirmed in dogs by Dirksen et al. (2016) [51], who showed that an increased number of miR-126 copies is typical only of chronic hepatitis, and of other liver diseases, such as hepatocellular adenoma, hepatocellular carcinoma, or acute hepatitis. This may indicate a higher specificity of this marker in the diagnosis of liver disease in dogs. Our results showed only an increased trend in miR-126 $(\mathrm{P}=0.053$; healthy $v s . \mathrm{H} 1)$, which along with the biochemical markers may indicate that the dogs were in a transition state from the acute to the chronic phases of hepatitis. It should also be emphasised that, after HEP supplementation, a decrease in the number of miR-126s $(\mathrm{H} 1 \mathrm{vs} . \mathrm{H} 28)$ was also observed, though this change also lacked statistical significance.

Overall, our results in EXP2 showed that liver diseases were accompanied by an increase in miR-122 ( $\mathrm{H} 1$ vs. H28), while the administration of commercial hepatoprotectant decreases it; this may indicate that treatment with HEP has a positive effect. It should be noted that there is only limited data in the literature on expression changes of miRNAs in the blood during liver diseases in dogs. We thus decided to support our research with further different diagnostic parameters. We also noted a decrease in ALT, AST, and GGT activity after administration of the commercial hepatoprotectant, which also confirms that this supplement improved liver metabolism.

The hepatoprotective properties of silymarin, containing silybin, are mainly associated with its antioxidant, antifibrotic, anti-inflammatory and cholagogic effect [14]. Moreover, silymarin accelerates liver regeneration [57]. On a molecular basis, silymarin inhibits lipid peroxidation and synthesis of reactive oxygen species. It has also been found that silymarin interacts with cell and mitochondrial membranes, modifying the flux of substances through them [14]. In a regular small animal practice, it might be challenging to accurately identify the exact liver disorder (following WSAVA guidelines) due to the lack of medical equipment and financial limitations, so symptomatic treatment with silybin is fully acceptable and reasonable.

An important limitation of our experiments is the fact that we did not study the hormonal profile of the dogs used for EXP2. Hence leading our study to be considered as a pilot, carried out following the positive result of the tested additives effect obtained during EXP1. Although we have published these results, EXP2 is not a complete study covering all aspects of canine liver disorders. We nonetheless believe that this may point to new directions of research on this issue. We also recognise that the EXP2 results require further research, which we plan to perform. 


\section{Conclusion}

In conclusion, we have confirmed that, in healthy dogs, supplementation with silybin at $12.75 \mathrm{mg}$ per 10 $\mathrm{kg}(8.5 \mathrm{mg}$ per $5 \mathrm{~kg}) \mathrm{BW}$, or with a commercial hepatoprotectant containing silybin at the same dose, does not interfere with the digestion of nutrients, and subsequently exerts no detrimental effect on liver performance, health, or blood parameters. In dogs with hepatopathies, supplementation with commercial hepatoprotectant containing silybin at a dose of $12.75 \mathrm{mg}$ per $10 \mathrm{~kg}(8.5 \mathrm{mg}$ per $5 \mathrm{~kg}) \mathrm{BW}$ resulted in a decrease in the activity of serum liver markers, which was accompanied by a decrease in the concentration of liver-specific miRNA molecules (mainly miR-122). Liver performance was hence improved. Overall, silybin supplementation has no detrimental impact on healthy dogs and supports liver performance in dogs with hepatopathies.

\section{Methods}

\section{Animals and experimental design: EXP1 and EXP2}

All experimental procedures were performed in accordance with the guidelines of the Local Ethical Committee for Animal Research (Ministry of Science and Higher Education, Poland) as well as in compliance with the ARRIVE guidelines. The study conformed to the 28/2020 statement of Local Ethical Committee in Poznan, Poland. The dog owners gave their informed consent in writing. The research consisted of two consecutive studies. The first, EXP1, surveyed a group of eighteen healthy laboratory adult beagle dogs ( $n=18$, nine females and nine males, 2 years old). In EXP1, a $3 \times 3$ Latin square design with 3 treatments (CON, HEP, SIL) and three periods was used. Each treatment was given to six dogs (three females and three males) in a given period, giving eighteen replicates. A commercial basic diet (Addvena, Poznań, Poland) composed of lamb (including fresh lamb meat 50\%), potatoes, peas, beet pulp, animal fat, potato protein, tomato puree, dried alfalfa, flaxseed, brewer's yeast, salmon oil, sodium phosphate dihydrate, chicory root, glucosamine, and chondroitin sulphate was the control diet (CON). The first experimental diet (HEP) was commercially available feed (CON) supplemented with commercial hepatoprotectant containing silybin (Hepaxan, Vebiot, Dębica, Poland), while the second diet (SIL) was CON supplemented with pure silybin. The diet for both groups contained silybin, pure or as a preparation, at a dose of $12.75 \mathrm{mg}$ per $10 \mathrm{~kg}$ ( $8.5 \mathrm{mg}$ per $5 \mathrm{~kg}$ ) body weight. EXP1 was divided into three periods, each lasting 28 days: this consisted of a 23-day adaptation phase (days 1 to 23) and a five-day total faecal collection phase (days 24 to 28), followed by a 12-day wash-out period. The experiment lasted 108 days (so each dog had three 28-day periods with 12-day wash-out periods between them). Titanium dioxide $\left(\mathrm{TiO}_{2}\right)$ was included in the diets as a digestion marker at $0.2 \%$ of diet. The analysed crude nutrient concentration in the diets and dietary fatty acid profile are presented in Table 1. Each dog was housed individually in a kennel that enabled social contact among animals, was fed twice a day, and had free access to water. During the adaptation phase, the dogs had access to an outside playground for exercise and socialisation. The maintenance energy requirement (MER) was estimated according to FEDIAF [58] 
and the diets met the MER of the dogs. Each animal taking part in the experiment was up to date on their vaccination and deworming schedules before beginning.

EXP2 used client-owned dogs $(n=15)$ referred to the University Centre for Veterinary Medicine at Poznań University of Life Sciences, in which a hepatic disorder was diagnosed. The diagnostic process did not reveal a specific etiology agent, therefore these cases were considered idiopathic. A profile of the dogs taking part in EXP2 can be found in Supplementary Table 1. The criteria we established for diagnosing a hepatic disorder were a clinical demonstration of at least one of the symptoms described as most prevalent in dogs with chronic hepatitis [48], including decreased appetite, lethargy/depression, icterus, ascites, PU/PD, vomiting, diarrhoea, or subsequently an increase in at least three out of these four liver markers: alanine aminotransferase (ALT), alkaline phosphatase (ALP), aspartate aminotransferase (AST), and gamma glutamyl transpeptidase (GGT). The exclusion criteria were infectious or parasitic diseases, systemic, neurological or traumatic diseases or general symptoms of food intolerance or allergy in the past. Moreover, individuals with confirmed hepatocarcinoma or other liver-associated cancers were excluded from the study. The dog owners were advised to begin supplementing their pets' diet with commercially available preparation containing silybin (Hepaxan, Vebiot, Dębica, Poland) at the dose recommended by the manufacturer (Supplementary Table 2).

\section{Health status and Body Condition Score (BCS): EXP1 and EXP2}

The average weight was $18.1 \mathrm{~kg}$ for males and $12.9 \mathrm{~kg}$ for females in EXP1, and $28.7 \mathrm{~kg}$ for males and $22.1 \mathrm{~kg}$ for females in EXP 2. In EXP1, body weight was measured on days 1 and 28 of the experimental period and feed intake was recorded daily. In EXP2, body weight was measured at the beginning (day 1) and at end (day 28) of supplementation with the hepatoprotectant. For all dogs in EXP1, the body condition score (BCS) was assessed throughout the experimental period in line with the recommendations of the World Small Animal Veterinary Association [59]. The dogs in EXP1 and EXP2 underwent weekly check-ups consisting of physical examination, including rectal temperature measurement, mucous membrane inspection, heart and lung auscultation, and stomach palpation (abdominal examination). The dogs were determined to be clinically healthy if the physical examination revealed no pathological findings.

\section{Blood sample collection: EXP1 and EXP2}

Blood samples were collected via cephalic venipuncture as follows:

1) EXP1: on the last day (day 28) of each treatment period at $6.00 \mathrm{AM}$.

2) EXP2: on the first day ( $\mathrm{H} 1)$ of the supplementation and 28 days later $(\mathrm{H} 28)$. 
In both EXP1 and EXP2, blood samples were collected in two vacutainer tubes. One of these contained $\mathrm{K}_{3}$ EDTA anticoagulant and was used for hematological examination; the second tube contained serum separator gel and was used to obtain serum for biochemical and miRNA examination, fatty acid profiles, and serum interleukin, immunoglobulin, and acute phase protein analysis. Blood from the second set of tubes was left at room temperature for blood clot formation and then centrifuged at $3500 \mathrm{rpm}$ for $10 \mathrm{~min}$ at $4{ }^{\circ} \mathrm{C}$ to obtain serum. The serum samples were transferred to Eppendorf tubes, labeled, sealed, and frozen at $-80{ }^{\circ} \mathrm{C}$ to await analysis.

\section{Hematology and serum biochemistry analysis: EXP1 and EXP2}

$\mathrm{CBC}$ was performed using a Vet $\mathrm{ABC}$ Animal Blood Counter automatic haematological analyser ( $\mathrm{ABX}$, Montpellier, France) with the following parameters: red blood cell count (RBC), neutrophil count (NEUT), lymphocyte count (LYM), monocyte count (MONO), eosinophil count (EOS), basophil count (BASO), hemoglobin (HEM), hematocrit (HTC), mean corpuscular volume (MCV), mean corpuscular hemoglobin $(\mathrm{CHC})$, mean corpuscular hemoglobin concentration (MCHC), white blood cells (WBC), and platelet (PLT) counts.

Biochemical analysis of ALT, ALP, AST, GGT, alpha amylase, total protein, total bilirubin, cholesterol, creatinine kinase (CK), fructosamine, glutamate dehydrogenase (GLDH), glucose (GLUC), creatinine, lactic dehydrogenase (LDH), lipase (DGGR), urea, triglycerides (TG), chloride, inorganic phosphorus, magnesium, potassium, sodium, calcium, albumin, globulin, and albumin/globulin ratio was carried out using a Dade Behring Dimension RxL analyser (Siemens Healthcare Diagnostics, Newark, DE, USA).

The reference ranges used to evaluate health status for the haematological and biochemical parameters were based on the Merck Veterinary Manual [60].

\section{Serum interleukins, immunoglobulins, and acute phase proteins analysis: EXP1}

In order to determine the concentrations of selected immunological parameters, commercially available species-specific quantitative ELISA kits were used as follows: for $\lg A$, $\lg G$, and $\lg E$ (Wuhan Fine Biotech, China), for IgM (Signalway Antibody, MA, USA), for IL1ß, IL4, IL6, IL8, and IL10 concentrations (Wuhan Fine Biotech, China), C-reactive protein (CRP) (BlueGene, Shanghai, China), serum amyloid-A (SAA) (ABclonal, Massachusetts, USA), haptoglobin (Cusabio, TX, USA). Prior to analysis, all serum samples were diluted (depending on assay range and the expected analyte concentration). For each test, serial dilutions of standards were tested in order to obtain a calibration curve, which was then computeradjusted. From this calibration curve, the values of the unknown protein concentration samples were calculated. All analyses were performed following the manufacturer`s instructions. 


\section{Diet and faeces sample collection: EXP1}

Diet samples were collected daily during the faecal collection phase (days 24 to 28 ) of each period and stored at $-20{ }^{\circ} \mathrm{C}$ for further analysis. Faeces were collected daily from day 24 to 28 , including at the time of daily walks. Freshly collected faeces samples were stored at $-20^{\circ} \mathrm{C}$. The total individual daily faecal output was weighed, mixed, and stored at $-20^{\circ} \mathrm{C}$ to await further analysis.

\section{Chemical analysis of diets and faeces and digestibility calculation: EXP1}

The faecal samples were dried for 72 hours at $55^{\circ} \mathrm{C}$, following AOAC International guidelines [61]. The dried faeces were milled in a laboratory mill (ZM200, Retsch, Haan, Germany) using a $1 \mathrm{~mm}$ sieve. The chemical composition of the feed and faeces samples was analysed following AOAC [61] method no. 934.01 for dry matter, method no. 976.05 for crude protein (using a Kjel-Foss Automatic 16210 analyser), and method no. 973.18 for crude fat (using a Soxtec System HT analyser). The apparent total tract digestibility (ATTD) of individual nutrients relative to the ratio of $\mathrm{TiO}_{2}$ was calculated as a percentage based on the following equation:

$$
\operatorname{ATTD}_{\square}=100-100\left(\left(\frac{\text { TiO }_{\frac{\mathrm{g}}{\mathrm{kg}} \text { diet }}}{\text { TiO }_{2 \frac{g}{\mathrm{~kg}} \text { feces }}}\right) \times\left(\frac{\text { nutrient }_{\frac{g}{\mathrm{~kg}} \text { feces }}}{\text { nutrient }_{\frac{g}{\mathrm{~kg}} \text { diet }}}\right)\right)
$$

\section{Dietary and serum fatty acid (FA) profile: EXP1}

FA concentration was determined using a gas chromatograph [62] with some modifications. Briefly, $3 \mathrm{~mL}$ of $2 \mathrm{M} \mathrm{NaOH}$ solution was added to $1 \mathrm{~g}$ feed or $0.5 \mathrm{ml}$ serum sample, respectively, in screw-cap Teflonstoppered tubes (glass, $15 \mathrm{~mL}$ ) for fat hydrolysis. The hydrolysed FA samples were incubated on a block heater at $90^{\circ} \mathrm{C}$ for $40 \mathrm{~min}$. Analysis of fatty acids methyl ester (FAME) was performed on a gas chromatograph (GC Bruker 456-GC, Billerica, MA, USA) equipped with a capillary column (100 m fusedsilica, $0.25 \mathrm{~mm}$ i.d., $0.25 \mu \mathrm{m}$ film thickness; Chrompack CP7420, Agilent HP). Fatty acids were identified based on their retention times and were expressed as $\mathrm{g} / 100 \mathrm{~g}$ FA. The observed peaks were identified by comparison of their retention times with FAME standards (37 FAME Mix, Sigma Aldrich, PA, USA) using a Galaxie Work Station 10.1 (Varian, CA).

\section{Urine samples and urinalysis: EXP1}

Free catch urine was collected on the last day of each feeding period using a Uripet urine collection device (Rocket Medical, Watford, England). Then $3 \mathrm{ml}$ of urine was stored at $-20^{\circ} \mathrm{C}$ and analysed for 
creatinine, cortisol, and pH using VetLab Station (IDEXX Poland) within two weeks of sampling.

\section{Serum miRNA expression: EXP1 and EXP2}

The investigation into the effects of the test compounds on the expression of miRNA in blood serum was performed in two experiments: In EXP1, we examined the effect of commercial hepatoprotectant and silybin supplementation on miRNAs expression in healthy dogs (EXP1). In EXP2, we investigated the effect of commercial hepatoprotectant on miRNA expression in dogs with liver disorders. The healthy dogs in EXP1 were used as the control group in EXP2.

MiRNA was isolated using QIAzol Lysis Reagent and miRNeasy Serum/Plasma Kit (Qiagen, Germany). Endogenous control was added to the samples during isolation (miRNeasy Serum/Plasma Spike-In Contro; Qiagen, Germany). Following extraction and elution of RNA, the samples were immediately frozen at $-80^{\circ} \mathrm{C}$. RNA content and relative purity were determined using the UV-Vis spectrophotometric method with a NanoPhotometer NP80 (Implen, Munich, Germany). Reverse transcription was performed using a miScript II RT kit, following the manufacturer's instructions. The master mix was prepared on cooling blocks and contained $4 \mu \mathrm{l}$ of 5x HiSpec Buffer, $2 \mu \mathrm{l}$ of 10x Nucleics Mix, $2 \mu \mathrm{l}$ of Reverse Transcriptase (RT), and $2 \mu \mathrm{l}$ of RNase-free water per reaction, giving a total volume of $20 \mu \mathrm{l} .10 \mu \mathrm{l}$ of the master mix was added to $10 \mu \mathrm{l}$ of the total RNA extracted from serum. The reaction was performed on a Mastercycler (Eppendorf, Germany) at $37^{\circ} \mathrm{C}$ for 60 minutes, followed by $95^{\circ} \mathrm{C}$ for 5 minutes to inactivate the RT. The relative expression of miRNAs (miR-192, miR-122 and miR-126) was measured by real-time PCR on QuantStudio12K Flex (Applied Biosystems, USA) using specific primers (MS00029883; Cf_miR-192_1 miScript, MS00029400; Cf_miR-122_1 miScript, MS00029428; Cf_miR-126_1 miScript; Qiagen, Germany) and miScript SYBR Green PCR kit (Qiagen, Germany). SNORD72 and RNU6-2 were used as endogenous controls (MS00033719; Hs_SNORD72_11, MS00033740; Hs_RNU6-2_11; Qiagen, Germany). Relative quantification of miRNA expression was calculated with the $2-\Delta \Delta C t$ method.

\section{Data analysis}

Both data sets for EXP1 and EXP2 were analysed with IBM SPSS Statistics 24 software (SPSS Inc, Armonk, USA). For each variable in EXP1 a repeated measure analysis (one-way ANOVA) with the Tukey test as post-hoc analysis was performed. A significant value was accepted at $p<0.05$. In both data sets Shapiro-Wilk test was applied to assess the data normality, whereas in data from EXP1 homogeneity of variance was evaluated through Levene's test. Variables in EXP2 were compared using the dependent Student's t-test for normally distributed variables with a significant value accepted at $p<0.05$.

\section{Abbreviations}

ALT: alanine aminotransferase; ALP: alkaline phosphatase; AST: aspartate aminotransferase; BASO: basophils; CON: control group; CRP: C-reactive protein; EOS: eosinophils; GLDH: glutamate 
dehydrogenase; GLUC: glucose; GGT: gamma glutamyl transpeptidase; $\mathrm{H} 1$ : first day of supplementation; H28: twenty-eighth day of supplementation; HEM: hemoglobin; HTC: hematocrit; HEP: group fed diet supplemented with commercial hepatoprotectant; LYM: lymphocytes; MCV: mean corpuscular volume; $\mathrm{MCH}$ : mean corpuscular hemoglobin; MCHC: mean corpuscular hemoglobin concentration; MONO: monocytes; NEUT: neutrophils; PLT: platelets; RBC: red blood cells; SAA: serum amyloid-A; SIL: group fed diet supplemented with pure silybin; WBC: white blood cells.

\section{Declarations}

\section{Ethics approval and consent to participate}

All experimental procedures were performed in accordance with the guidelines of the Local Ethical Committee for Animal Research (Ministry of Science and Higher Education, Poland) and in compliance with the ARRIVE guidelines. The study conformed to the 28/2020 statement of Local Ethical Committee in Poznan, Poland. The dog owners gave their informed consent in writing.

\section{Consent for publication}

Not applicable.

\section{Availability of data and materials}

The datasets used and analysed in the current study are available from the corresponding author on reasonable request.

\section{Competing interests}

The authors declare that they have no competing interest.

\section{Funding}

This research received no specific grant from any funding agency in the public, commercial, or not-forprofit sectors.

\section{Author's contributions}

MG and AC conceived and designed the study. JG and MA drafted the manuscript. MPM, PAK, AC, MSS performed the analyses. KL collected the data and provided the statistical description. MSS and AC provided intellectual input, and VS provided the intellectual input and language correction. All authors contributed to the interpretation of the data and the writing and editing of the manuscript.

\section{Acknowledgements}

Not applicable. 


\section{References}

1. Becvarova I, Prochazka D, Chandler ML, Meyer H. Nutrition education in European veterinary schools: Are European veterinary graduates competent in nutrition? J. Vet. Med. Educ. 2016;43(4):349-58.

2. Di Cerbo A, Morales-Medina JC, Palmieri B, Pezzuto F, Cocco R, Flores G, lannitti T. Functional foods in pet nutrition: Focus on dogs and cats. Res. Vet. Sci. 2017;112:161-6.

3. Atkins C, Bonagura J, Ettinger S, Fox P, Gordon S, Haggstrom J, Hamlin R, Keene B, Luis-Fuentes V, Stepien R. Guidelines for the diagnosis and treatment of canine chronic valvular heart disease. J. Vet. Intern. Med. 2009;23:1142-50.

4. Davies T, Everitt S, Cobb M. Variation in the management of congestive cardiac failure in dogs. Vet. Rec. 2015;176(17):435.

5. Lippi G, Mattiuzzi C, Gomar FS. Red meat consumption and ischemic heart disease: A systematic literature review. Meat Sci. 2015;108:32-6.

6. Weidner N, Verbrugghe A. Current knowledge of vitamin D in dogs. Crit. Rev. Food. Sci. Nutr. 2017;57(18):3850-9.

7. Hall JA, Fritsch DA, Yerramilli M, Obare E, Yerramilli M, Jewell DE. A longitudinal study on the acceptance and effects of a therapeutic renal food in pet dogs with IRIS-Stage 1 chronic kidney disease. J. Anim. Physiol. Anim. Nutr. (Berl.) 2018;102(1):297-307.

8. Toresson L, Steiner JM, Razdan P, Spodsberg E, Olmedal G, Suchodolski JS, Spillmann T. Comparison of efficacy of oral and parenteral cobalamin supplementation in normalising low cobalamin concentrations in dogs: A randomised controlled study. Vet. J. 2018;232:27-32.

9. Sharma V, Singh P, Rani A. Antimicrobial Activity of Trigonella foenum-graecum L. (Fenugreek). Eur. J. Exp. Biol. 2017;07(01).

10. Gupta RC, Srivastava A, Lall R, editors. Nutraceuticals in Veterinary Medicine. Springer; 2019.

11. Omojate GC, Enwa FO, Jewo AO, Eze CO. Mechanisms of Antimicrobial Actions of Phytochemicals against Enteric Pathogens - A Review. J Pharm Chem Biol Sci. 2014;2(2):77-85.

12. Kalra EK. Nutraceutical: Definition and introduction. AAPS J. 2003;5(3):1-2.

13. Watson PJ, Roulois AJA, Scase TJ, Irvine R, Herrtage ME. Prevalence of hepatic lesions at postmortem examination in dogs and association with pancreatitis. J Small Anim Pract. 2010;51(11):566-72.

14. Gogulski M, Ardois M, Grabska J, Libera K, Szumacher-Strabel M, Cieślak A, Strompfova V. Dietary supplements containing silymarin as a supportive factor in the treatment of canine hepatopathies. Med. Weter. 2020;76:700-8.

15. Webb C, Twedt D, Meyer D. Copper-associated liver disease in Dalmatians: A review of 10 dogs (1997-2001). J. Vet. Intern. Med. 2002;16:665-668.

16. Spevakow AB, Nibblett BM, Carr AP, Linn KA. Chronic mesenteric volvulus in a dog. Can. Vet. J. 2010;51(1):85-8. 
17. Norton RD, Lenox CE, Manino P, Vulgamott JC. Nutritional considerations for dogs and cats with liver disease. J. Am. Anim. Hosp. Assoc. 2016;52(1):1-7.

18. Daumas C, Paragon B-M, Thorin C, Martin L, Dumon H, Ninet S, Nguyen P. Evaluation of eight commercial dog diets. J. Nutr. Sci. 2014;3:1-5.

19. Ghost A, Ghost T, Jain S. Silymarin: A review on the pharmacodynamics and bioavailability enhancement approaches. J. Pharm. Sci. Technol. 2010;2(10):348-55.

20. Karimi G, Vahabzadeh M, Lari P, Rashedinia M, Moshiri M. Silymarin: A promising pharmacological agent for treatment of diseases. Iran. J. Basic Med. Sci. 2011;14(4):308-17.

21. Martínez G, Diéguez SN, Rodríguez E, Decundo JM, Romanelli A, Fernández Paggi MB, Pérez Gaudio DS, Amanto FA, Soraci AL. Effect of Cynara scolymus and Silybum marianum extracts on bile production in pigs. J. Appl. Anim. Res. 2018;46(1):1059-63.

22. Nikzad Z, Chaji M, Mirzadeh K, Mohammadabadi T, Sari M. Effect of different levels of milk thistle (Silybum marianum) in diets containing cereal grains with different ruminal degradation rate on rumen bacteria of Khuzestan buffalo. Iran. J. Appl. Anim. Sci. 2017;7(3):401-9.

23. Hasheminejad SA, Fani Makki O, Ansari Nik H, Ebrahimzadeh A. The effects of aflatoxin B1 and silymarin-containing milk thistle seeds on ileal morphology and digestibility in broiler chickens. Vet. Sci. Dev. 2015;5(1).

24. Chon SK, Kim NS. Evaluation of silymarin in the treatment of asymptomatic Giardia infections in dogs. Parasitol. Res. 2005;97(6):445-51.

25. Sgorlon S, Stefanon B, Sandri M, Colitti M. Nutrigenomic activity of plant derived compounds in health and disease: Results of a dietary intervention study in dog. Res Vet Sci. 2016;109:142-8.

26. Kocatürk M, Inan OE, Levent P, Yilmaz Z. Protective effects of S-adenosylmethionine (SAMe) and silybin on hepatorenal and hemostatic functions in dogs with endotoxemia. Turkish J Vet Anim Sci. 2016;40(6):788-96.

27. Skorupski, KA, Hammond, GM, Irish AM, Kent MS. Prospective randomized clinical trial assessing the efficacy of denamarin for prevention of CCNU-induced hepatopathy in tumor-bearing dogs. J. Int. Vet. Med. 2011;838-45.

28. Mosallanejad B, Avizeh R, Najafzadeh, Varzi H, Pourmehdi M. Evaluation of prophylactic and therapeutic effects of silymarin on mebendazole-induced hepatotoxicity in cats. Comp. Clin. Path. 2012;21(5):681-5.

29. Najafzadeh $H$, Jalali MR, Morovvati $H$, Taravati F. Comparison of the prophylactic effect of silymarin and deferoxamine on iron overload-induced hepatotoxicity in rat. J. Med. Toxicol. 2010;6(1):22-6.

30. Avizeh R, Najafzadeh H, Razijalali M, Shirali S. Evaluation of prophylactic and therapeutic effects of silymarin and $\mathrm{N}$-acetylcysteine in acetaminophen-induced hepatotoxicity in cats. J. Vet. Pharmacol. Ther. 2010;33:95-9.

31. Gaskill CL, Miller LM, Mattoon JS, Hoffmann WE, Burton SA, Gelens HCJ, Ihle SL, Miller JB, Shaw DH, Cribb AE. Liver histopathology and liver and serum alanine aminotransferase and alkaline phosphatase activities in epileptic dogs receiving phenobarbital. Vet. Pathol. 2005;42(2):147-60. 
32. Alvarez L, Whittemore JC. Liver enzyme elevations in dogs: physiology and pathophysiology. Compend. Contin. Educ. Vet. 2009.

33. Fujiwara M, Mori N, Sato T, Tazaki H, Ishikawa S, Yamamoto I, Arai T. Changes in fatty acid composition in tissue and serum of obese cats fed a high fat diet. BMC Vet. Res. 2015;11(1):1-8.

34. Sun R, Xu D, Wei Q Zhang B, Aa J, Wang G, Xie Y. Silybin ameliorates hepatic lipid accumulation and modulates global metabolism in an NAFLD mouse model. Biomed. Pharmacother. 2020;123:109721.

35. Ramakrishnan G, Elinos-Báez CM, Jagan S, Augustine TA, Kamaraj S, Anandakumar P, Devaki T. Silymarin downregulates COX-2 expression and attenuates hyperlipidemia during NDEA-induced rat hepatocellular carcinoma. Mol Cell Biochem. 2008;313(1-2):53-61.

36. Poruba M, Anzenbacher P, Racova Z, Oliyarnyk O, Hüttl M, Malinska H, Markova I, Gurska S, Kazdová $L$, Vecera $R$. The effect of combined diet containing n-3 polyunsaturated fatty acids and silymarin on metabolic syndrome in rats. Physiol Res. 2019;68:s39-50.

37. Feng B, Meng R, Huang B, Bi Y, Shen S, Zhu D. Silymarin protects against renal injury through normalization of lipid metabolism and mitochondrial biogenesis in high fat-fed mice. Free Radic. Biol. Med. 2017;110:240-9.

38. Fraschini F, Demartini G, Esposti D. Pharmacology of silymarin. Clin. Drug Investig. 2002;22(1):5165.

39. Fukunaga K, Saito M, Muto M, Mishima K, Fujiwara M, Orito K. Effects of urine pH modification on pharmacokinetics of phenobarbital in healthy dogs. J. Vet. Pharmacol. Ther. 2008;31(5):431-6.

40. Johnson VJ, Osuchowski MF, He Q, Sharma RP. Physiological responses to a natural antioxidant flavonoid mixture, silymarin, in BALB/c mice: Il. alterations in thymic differentiation correlate with changes in c-myc gene expression. Planta Med. 2002;11:961-5.

41. Chumann J, Prockl J, Kiemer AK, Vollmar AM, Bang R, Tiegs G. Silibinin protects mice from T celldependent liver injury. J. Hepatol. 2003;39:333-40.

42. Morishima C, Shuhart MC, Wang CC, Paschal DM, Apodaca MC, Liu Y, Sloan DD, Graf TN, Oberlies $\mathrm{NH}$, Lee DY, Jerome KR, Polyak SJ. Silymarin inhibits in vitro T-cell proliferation and cytokine production in hepatitis C virus infection. Gastroenterology 2010;138:671-81.

43. Moore KW, O'Garra A, de Waal Malefyt R, Vieira P, Mosmann TR. Interleukin-10. Ann. Rev. Immunol. 1993;11:165-90.

44. Zurawski G, de Vries JE. Interleukin-13, an interleukin 4-like cytokine that acts on monocytes and B cells, but not on T cells. Immunol. Today 1994;15:19-26.

45. Mitchell RE, Hassan M, Burton BR, Britton G, Hill EV, Verhagen J, Wraith DC. IL-4 enhances IL-10 production in Th1 cells: Implications for Th1 and Th2 regulation. Sci. Rep. 2017;7:113-15.

46. Yano M, Kumada H, Kage M, Ikeda K, Shimamatsu K, Inoue O, Hashimoto E, Lefkowitch JH, Ludwig J, Okuda K. The long-term pathological evolution of chronic hepatitis C. Hepatology 1996;23:1334-40.

47. Ghany MG, Kleiner DE, Alter H, Doo E, Khokar F, Promrat K, Heiron D, Park Y, Liang TJ, Hoofnagle JH. Progression of fibrosis in chronic hepatitis C. Gastroenterology 2003;124:97-104. 
48. Webster CR, Center SA, Cullen JM, Penninck DG, Richter KP, Twedt DC, Watson PJ. ACVIM consensus statement on the diagnosis and treatment of chronic hepatitis in dogs. J. Vet. Intern. Med. 2019;33(3):1173-200.

49. Karakurt E, Dag S. Protective effect of silymarin on diethylnitrosamine-induced hepatocellular carcinoma model in Wistar rats; cancer patterns and cytological variants. Ataturk Univ. Vet. Bilim. Derg. 2020;15(1):43-50.

50. Liu CH, Jassey A, Hsu HY, Lin LT. Antiviral activities of silymarin and derivatives. Molecules 2019;24(8):1-15.

51. Dirksen K, VerzijI T, Grinwis GC, Favier RP, Penning LC, Burgener IA, van der Laan LJ, Fieten H, Spee B. Use of serum microRNAs as biomarker for hepatobiliary diseases in dogs. J. Vet. Intern. Med. 2016;1816-23.

52. Ebrahimi F, Gopalan V, Smith RA, Lam AK. MiR-126 in human cancers: Clinical roles and current perspectives. Exp. Mol. Pathol. 2014;96:98-107.

53. Hsu S, Ghoshal K. MicroRNAs in liver health and disease. Curr. Pathobiol. Rep. 2013;53-62.

54. Koenig EM, Fisher C, Bernard H, Wolenski FS, Gerrein J, Carsillo M, Gallacher M, Tse A, Peters R, Smith A, Meehan A, Tirrell S, Kirby P. The beagle dog MicroRNA tissue atlas: Identifying translatable biomarkers of organ toxicity. BMC Genomics 2016;17:649.

55. Oosthuyzen W, Ten Berg PW, Francis B, Campbell S, Macklin V, Milne E, Gow AG, Fisher C, Mellanby RJ, Dear JW. Sensitivity and specificity of microRNA-122 for liver disease in dogs. J. Vet. Intern. Med. 2018;32:1637-1644.

56. Schueller F, Roy S, Vucur M, Trautwein C, Luedde T, Roderburg C. The role of miRNAs in the pathophysiology of liver diseases and toxicity. Int. J. Mol. Sci. 2018;19.

57. Center SA. Metabolic, antioxidant, nutraceutical, probiotic, and herbal therapies relating to the management of hepatobiliary disorders. Vet. Clin. North Am. Small Anim. Pract. 2004;34(1):67-172.

58. FEDIAF Nutritional Guidelines for Complete and Complementary Pet Food for Cats and Dogs, 2020.

59. WSAVA Nutritional Assessment Guidelines Task Force Members. Nutritional assessment guidelines. J. Small Anim. Pract. 2011;52:385-396.

60. Lines S, C Kahn, The Merck Veterinary Manual. 10 ed. Merck Manuals; 2010.

61. Association of Official Analytical Chemists (AOAC), Official Methods of Analysis. 18 ed., ed. Horwitz W, Latimer W. AOAC International, Gaithersburg, MD; 2007.

62. Szczechowiak J, Szumacher-Strabel M, El-Sherbiny, Pers-Kamczyc E, Pawlak P, Cieslak A. Rumen fermentation, methane concentration and fatty acid proportion in the rumen and milk of dairy cows fed condensed tannin and/or fish-soybean oils blend. Anim. Feed Sci. Technol. 2016;216:93-107.

\section{Figures}



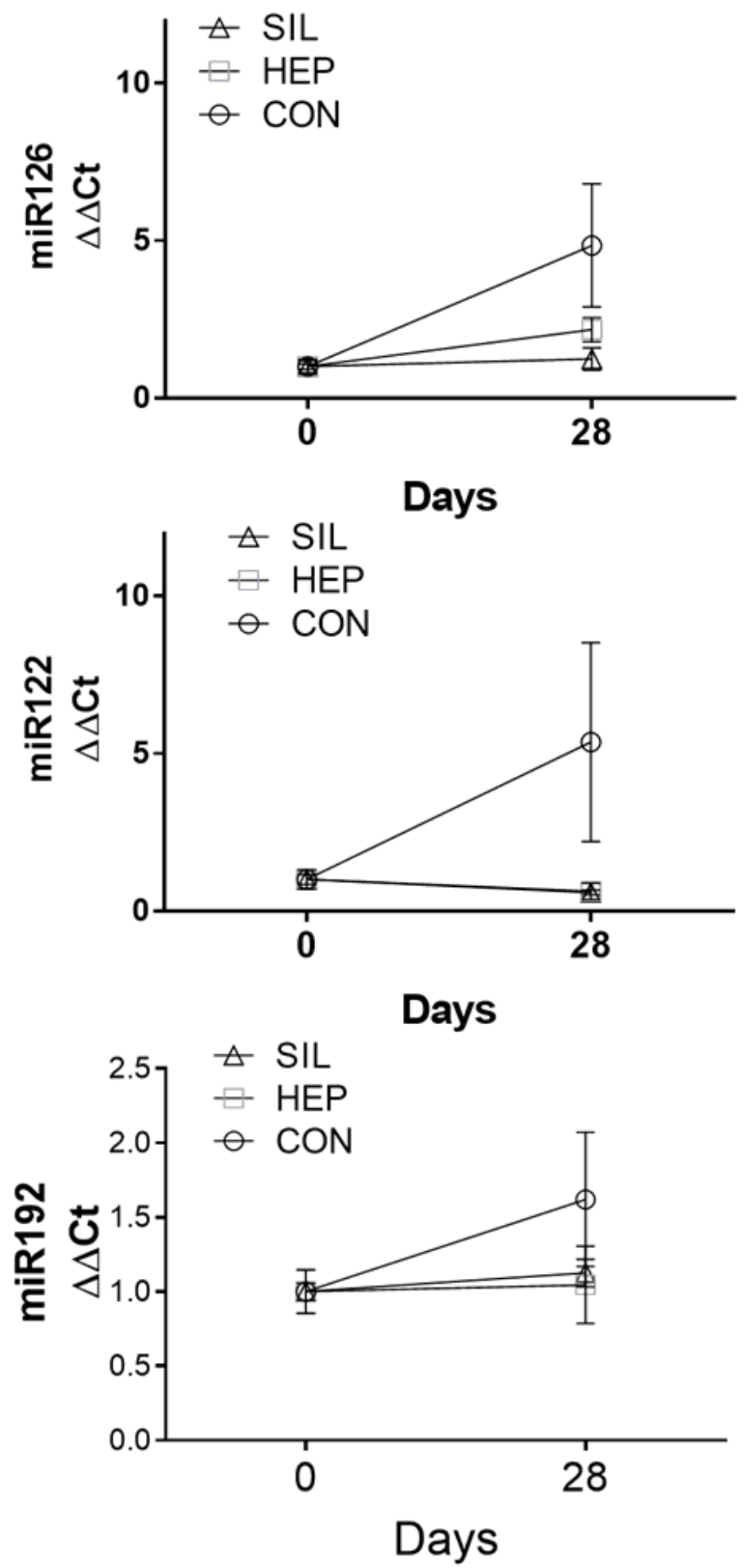

Figure 1

miRNA serum concentration in the healthy dogs in EXP1. CON: control group; HEP: group fed diet supplemented with commercial hepatoprotectant containing silybin; SIL: group fed diet supplemented with pure silybin. The values are expressed as mean \pm SD. 

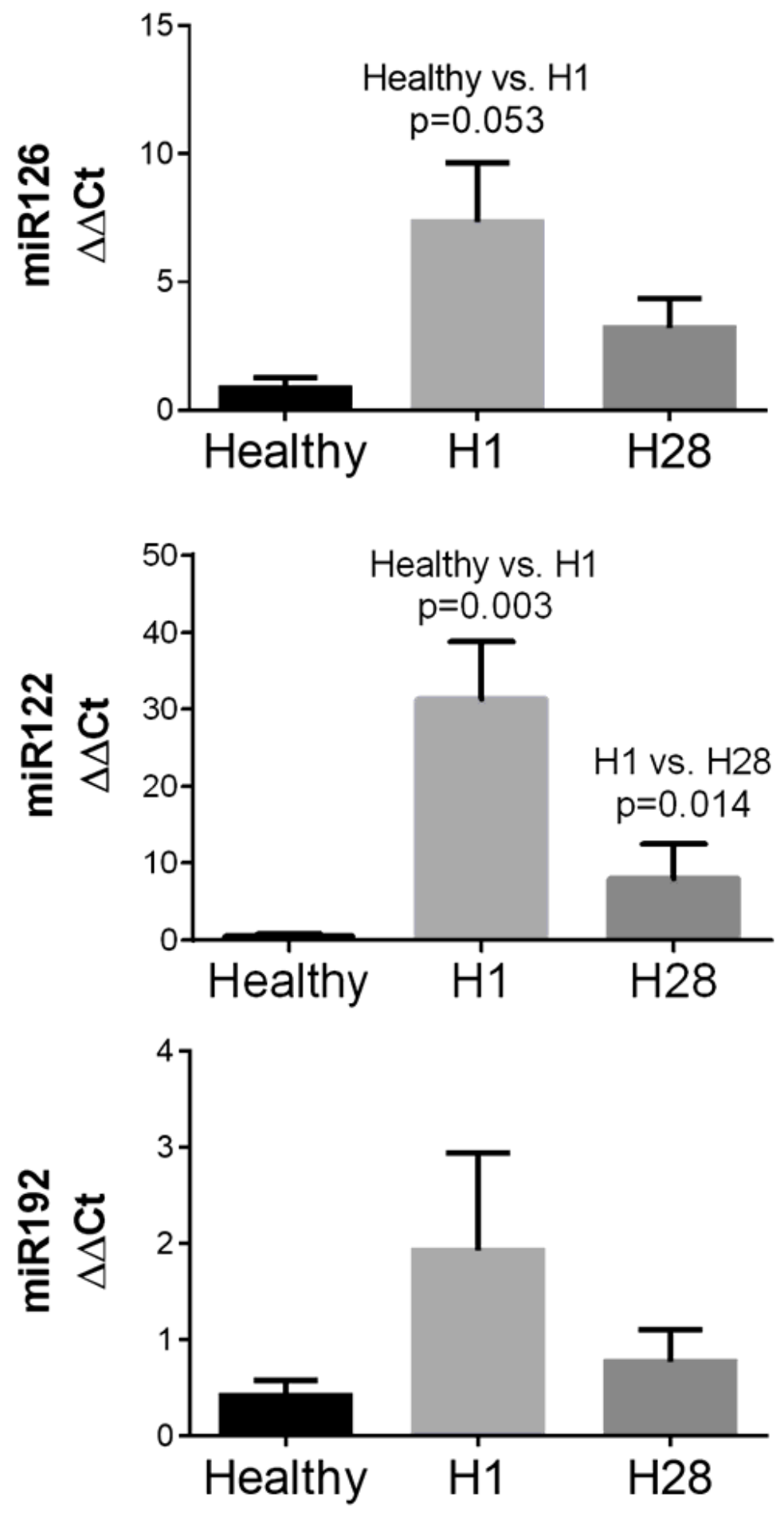

Figure 2

miRNA serum concentration in dogs with hepatopathies at the beginning of the supplementation with commercial hepatoprotectant containing silybin $(\mathrm{H} 1)$ and 28 days later $(\mathrm{H} 28)$ in EXP2. The values are expressed as mean \pm SD.

\section{Supplementary Files}


This is a list of supplementary files associated with this preprint. Click to download.

- SupplementaryTable1andSupplementaryTable2.pdf 